\title{
O que se mostra quando pedagogas em formação escrevem sobre suas experiências com a matemática?
}

What is shown when training pedagogues write about your experiences with mathematics?

Letícia Queiroz Maffei ${ }^{1}$

João Alberto da Silva²

\section{Resumo}

Neste artigo apresentamos o viés metacognitivo de uma pesquisa de doutorado que buscou verificar como se mostram os afetos em relação à Matemática na escrita de acadêmicas de um curso de Pedagogia de uma universidade do sul do Estado do Rio Grande do Sul. A pesquisa, conduzida sob um viés fenomenológico, teve como instrumento de coleta de dados cadernetas de metacognição que foram escritas pelas acadêmicas durante a disciplina de Metodologia do Ensino da Matemática, momento no qual a Matemática é formalmente estudada no âmbito da formação em Pedagogia. A escrita nas cadernetas foi utilizada no sentido de elaboração dos dados da pesquisa, mas, principalmente, em uma perspectiva formativa. Percebeu-se a importância de que para lidar com o ensinar e o aprender o professor reflita sobre como esses processos acontecem na sua própria relação com a disciplina de Matemática. Nesta perspectiva de voltar-se a si pode-se ser capaz de identificar e ressignificar memórias, crenças, percepções e autoconceitos que muitas vezes estão atrelados às questões cognitivas.

Palavras chave: metacognição; formação de professores; pedagogia; matemática; fenomenologia

\section{Abstract}

This paper presents the metacognitive point of view of a discussion that integrates a doctoral research that sought to verify the affections in relation to Mathematics in the writing of academics from pedagogy from a southern university of Rio Grande do Sul. The research conducted under a phenomenological bias had as data collection tool, the metacognition notebooks that were written by the academics during the Mathematics Teaching Methodology discipline, at which point mathematics is formally studied in the scope of Pedagogy. Writing in the notebooks was used in the sense of elaborating the research data and also mainly in a formative perspective. It was observed that to deal with teaching and learning, it is important for the teacher to reflect on how these processes happen in relation with the Mathematics discipline. In this perspective, it can be able to identify and re-signify memories, beliefs, perceptions, and self-concepts that are often tied to cognitive issues.

Keywords: metacognition; teacher training; pedagogy; mathematics; phenomenology

\footnotetext{
${ }^{1}$ Universidade Federal do Rio Grande | letimaffei@gmail.com

${ }^{2}$ Universidade Federal do Rio Grande | joaosilva@furg.br
} 


\section{Introdução}

O estudo aqui apresentado consiste em uma pesquisa qualitativa (BOGDAN; BIKLEN, 1994), realizada sob um viés fenomenológico (BICUDO, 2010; BICUDO, 2011; KLÜBER; BURAK, 2008; MARTINS; BICUDO, 2006; REZENDE, 1990), que buscou refletir sobre como os afetos em relação à Matemática se mostram na formação inicial de pedagogas. A formação em Pedagogia não tem sua ênfase diretamente relacionada à Matemática, porém esta disciplina compõe o rol de saberes necessários aos pedagogos. Pensar nos afetos em relação à Matemática no âmbito da Pedagogia, mais precisamente de acadêmicas em formação, é voltar o olhar para aspectos subjetivos que muitas vezes são esquecidos durante as formações, em detrimento de acúmulos de conhecimentos teóricos e práticos.

Ainda que em nossa pesquisa não tenham se mostrado exclusivamente aspectos negativos da relação com a Matemática, foram estes que inicialmente desencadearam nossas inquietações. Estudos como o de Thomaz (1996) e Carvalho (2009) destacam o fato de que muitos dos que optam por cursos como Pedagogia ou Magistério demonstram e afirmam não gostar de Matemática. Segundo Thomaz (1996, p. 13), esses afetos se mostram como um dado significativo para o processo de aprendizagem do estudante, à medida que "o professor, é, também, um motivador da aprendizagem, é capaz de despertar desejos nos alunos; portanto, quem não gosta de 'algo' como pode fazê-lo despertar interesse em outro?".

Como destaca Sadovsky (2010), frequentemente, os docentes afirmam que a Matemática está em toda parte, na tentativa de mostrar aos alunos a importância de tal estudo. Porém, embora tal importância de fato exista, a Matemática não é visível em todo lugar. Além disso, segundo Albarello (2014, p. 14) "parece ser senso comum que a Matemática é para indivíduos dotados de habilidades diferenciadas. E essa postura talvez venha de épocas em que essa área de conhecimento era privilégio de alguns".

Deste modo, Carvalho (2009, p. 17) destaca que "se o professor, durante a sua formação, não vivenciar a experiência de sentir-se capaz de entender Matemática e de construir algum conhecimento matemático, dificilmente aceitará tal capacidade em seus alunos". Nessa perspectiva do sentir-se capaz podem emergir conceitos como a fobia ou o encantamento, abordagens as quais são exploradas nos estudos de Albarello (2014) e, mais especificamente pelo viés da matofobia temos os estudos de Felicetti (2007).

Sabendo que o aprendizado matemático inicia desde muito cedo, a fobia pela disciplina também é trazida por alguns desde muito cedo. A matemática entra na vida dos alunos no início de suas atividades escolares. Toda a estrutura de um aprendizado com sucesso é construída desde a pré-escola, com as pequenas noç̃̃es aritméticas. O primeiro contato com a matemática formal é muito significativo para o despertar do gosto pela mesma. Práticas interessantes e bem elaboradas fazem desse momento uma situação de satisfação e entusiasmo e que marca e constrói na vida do educando uma afinidade com a disciplina (ALBARELLO, 2014, p. 44).

Albarello explicita essa relação que vai sendo constituída desde os primeiros contatos com a disciplina ainda na infância, portanto tem o pedagogo uma função fundamental nesse momento de apresentação da criança à Matemática que irá formalmente conhecer ao longo de sua trajetória escolar. Já Felicetti (2007) ao se apropriar do termo "matofobia" considera-o como um sentimento negativo a respeito da Matemática. Tal sentimento é 
identificado inicialmente na escola, onde a Matemática acaba se tornando o vilão na vida escolar de muitos alunos. A pesquisadora coloca o sentimento de "matofobia" como um fator que pode vir a contribuir para o fracasso escolar de modo que não só prejudique a aprendizagem da Matemática, mas que possa também interferir no desenvolvimento de outros conteúdos curriculares.

Mostram-se, nas crenças e concepções sobre a Matemática, alguns aspectos fortemente arraigados. Ao pensarmos nos afetos em Matemática, nos remetemos a Gómez Chacón (2003) que destaca o aspecto cíclico da relação que se estabelece entre afetos emoções, atitudes e crenças - e aprendizagem. A pesquisadora afirma que se...

por um lado, a experiência do estudante ao aprender matemática provoca diferentes reações e influi na formação de suas crenças. Por outro, as crenças defendidas pelo sujeito têm uma consequência direta em seu comportamento, em situações de aprendizagem e em sua capacidade de aprender (GÓMEZ CHACÓN, 2003, p. 23).

Devemos pensar nesses afetos também no sentido do autoconceito que o estudante constrói de si, enquanto aprendiz de Matemática, ao receber contínuas mensagens do que significa conhecer Matemática e sobre o significado social do que está aprendendo. Para Gómez Chacón (2003), o autoconceito está relacionado com as atitudes, a visão do mundo matemático e a identidade social do estudante. Sendo assim, o autoconceito tem grande influência na visão que este estudante concebe de Matemática e sua reação para com ela.

Nestas primeiras linhas apresentamos um panorama do que se mostra no âmbito dos afetos e a necessidade de um trabalho no que tange aos aspectos metacognitivos no processo formativo das acadêmicas. O pensar e escrever sobre o que conhecem de modo que sentimentos e memórias possam sair de espaços onde estavam acomodados emoldurando crenças e percepções sobre si e a Matemática e ganhar novas significações. Nas linhas que seguem apresentaremos como tais escritas se constituíram nos dados desta pesquisa e o que emerge a partir da análise dos mesmos.

\section{Cadernetas de Metacognição - aporte teórico e o corpus de análise}

Como já mencionado anteriormente, nosso estudo foi conduzido junto a uma turma de acadêmicas de um curso de Pedagogia ${ }^{3}$, de uma universidade pública do sul do Estado do Rio Grande do Sul ${ }^{4}$, coletando escritos pessoais realizados durante 2016, ano em que cursavam a disciplina de Metodologia do Ensino da Matemática para Crianças, Jovens e Adultos. Tal disciplina é ministrada regularmente, durante todo o terceiro ano de curso, com uma carga horária semanal de duas horas no primeiro semestre e quatro horas no segundo semestre, sendo o momento no qual a Matemática e suas metodologias são diretamente trabalhadas com as acadêmicas. A solicitação das escritas se deu em meio às metodologias

\footnotetext{
3 Foram consideradas as escritas de 21 acadêmicas que assinaram um Termo de Consentimento Livre e Esclarecido permitindo que suas produções compusessem nosso corpus de análise.

${ }^{4}$ Por questões de manutenção do anonimato, a identificação foi parcialmente suprimida e será anunciada na versão final do texto.
} 
de trabalho utilizadas na disciplina e, posteriormente, foram selecionados os textos que seriam integrados ao corpus de análise do estudo. Durante todos os encontros ${ }^{5}$, o período final das aulas era dedicado a essas escritas.

Estes textos, que se configuraram como os dados a serem analisados, foram coletados a partir de uma aposta na ideia de metacognição. Para Portilho (2004), a educação reduziu por muito tempo sua preocupação ao que se mostrava evidente nas condutas dos sujeitos e acabou por deixar de lado aspectos importantes, tais como, os recursos internos usados por quem aprende para que seja consciente de seu processo de aprendizagem. A teoria da metacognição, segundo a pesquisadora, coloca o sujeito aprendente em uma condição ativa, conduzindo sua aprendizagem sem limitá-la a espera por impulsos procedentes do meio para realizar uma ou outra tarefa. O movimento interno em busca do conhecimento do conhecer e o olhar para dentro de si, na visão de Portilho, levam a metacognição a ser uma necessidade sentida.

Imagine como seria nossa vida se não tivéssemos consciência de nossos próprios pensamentos. Como poderíamos planejar nossas ações e corrigilas quando estas não ocorrem como esperado? Como poderíamos monitorar nossos comportamentos e adequá-los frente a cada exigência com a qual nos deparamos? Como poderíamos escolher a maneira mais adequada de estudar ao longo de nossa vida acadêmica? Podemos fazer tudo isto a cada instante devido à capacidade de nosso pensamento de pensar-se a si mesmo (JOU; SPERB, 2006, p. 177).

Jou e Sperb (2006), após levantarem tais questionamentos e reflexões, destacam que a metacognição é essa compreensão que as pessoas têm acerca do próprio processamento cognitivo. "Etimologicamente, metacognição significa para além da cognição, ou seja, a faculdade de conhecer o próprio ato de conhecer" (MAXIMO; ABIB, 2013, p. 2233, grifos dos autores). O campo de estudo da metacognição despontou nos anos 70, mas intensificou-se nos anos 80 e 90. (JOU; SPERB, 2006) No Brasil, surgem os primeiros estudos aliando metacognição e ensino-aprendizagem de Matemática em meados de 1997 (SECAFIM; DARSIE, 2017). Resgataremos algumas definições atreladas à metacognição.

Pouco a pouco, a definição de metacognição foi ampliada e incluiu, não apenas "pensamentos sobre pensamentos", como fora antes considerado, mas as seguintes noções também: conhecimento sobre um conhecimento, processos, e estados cognitivos e afetivos; e a capacidade de monitorar e regular conscientemente e deliberadamente 0 conhecimento, processos e estados cognitivos e afetivos (PAPALEONTIOU-LOUCA, 2008, p. 3, tradução nossa).

Flavell (1979), considerado o pai da metacognição, distingue ainda conhecimento metacognitivo de experiência cognitiva. $O$ conhecimento metacognitivo estaria associado basicamente aos conhecimentos ou crenças a respeito dos fatores ou variáveis que atuam e interagem afetando o resultado dos processos cognitivos. Tais fatores ou variáveis são divididos em três categorias: pessoa, tarefa e estratégia. Flavell (1979) inclusive aponta como exemplo a criança que adquire a crença de que é melhor na aritmética do que na

\footnotetext{
${ }^{5}$ Foram um total de 14 encontros durante o primeiro semestre da disciplina.
} 
linguagem. Já as experiências metacognitivas estão mais associadas à percepção e ao âmbito afetivo, consistindo nas impressões que poderão ocorrer diante da realização de uma tarefa (JOU; SPERB, 2006; RIBEIRO, 2003). A escrita das cadernetas de metacognição representa um momento importante de reflexão tanto no que tange às crenças introjetadas, quanto às percepções trazidas pelas acadêmicas e que vão sendo ressignificadas no ato da escrita e resgate desses aspectos, paralelamente aos estudos realizados ao longo da disciplina de Metodologia do Ensino da Matemática.

Romainville, Noël e Wolfs (1995) evidenciam o fato de que a metacognição é uma operação mental de segunda ordem, ou seja, uma operação mental realizada em relação a outra operação mental. Os autores colocam que a metacognição seria um caso particular da cognição, porém não em relação a um objeto externo ao aprendiz, mas um fenômeno que ocorre internamente. Para exemplificar tal explicação os autores apresentam a situação de um aluno diante da leitura de um texto. Se as questões que emergem durante a leitura do texto são feitas em relação ao material, então a operação está sendo realizada sobre o conteúdo, porém se o aluno analisa suas estratégias de leitura e seu próprio comportamento como leitor então é uma operação mental exercida sobre suas próprias operações mentais, ou seja, metacognição. É na perspectiva de pensar um estudo da Matemática que justamente extrapolasse o domínio de conceitos ou técnicas que foram utilizadas as cadernetas, no intuito de levar a um pensar sobre o próprio comportamento enquanto sujeito aprendente da disciplina.

Bustingorry e Mora (2008) reforçam a importância da metacognição para a educação destacando o fato de que a criança é um aprendiz constantemente confrontado com novas tarefas de aprendizagem, mas é necessário que eles aprendam a aprender, pois assim podem se tornar aprendizes autônomos. Para que se tenha essa autonomia intelectual, Leite e Darsie (2011, p. 183) reforçam a necessidade de atividades metacognitivas nos ambientes escolares, pois "além de promoverem o desenvolvimento da própria cognição do estudante, os levam a refletir sobre o conhecimento de seus próprios processos cognitivos". Segundo Carvalho (2007, p. 13)

é inegável que os indivíduos enfrentam novas exigências educativas, visto que necessitam, via construção do seu próprio conhecimento, ser participantes ativos de uma sociedade em permanente mudança. Dessa forma, a principal implicação para a educação passa a ser a otimização das capacidades cognitivas, afetivas e sociais de todos; atendendo à necessidade de uma cultura de aprendizado.

Porém, a autora reforça que a realização de práticas metacognitivas terá um maior potencial para ser conduzida entre "professores que também atuem metacognitivamente como aprendizes e mestres, planificando, monitorando e avaliando suas atuações docentes e adquirindo assim consciência de suas próprias competências e limitações" (CARVALHO, 2007, p. 76). Ao conduzir a escrita das cadernetas com as acadêmicas da pedagogia instigamos à essa postura de buscarem conhecer e compreender suas capacidades pessoais, competências e dificuldades, para que possam intervir em seus próprios processos de aprendizagem e assim também conduzir práticas, enquanto professoras, que levem as crianças a uma maior autonomia. Carvalho (2007, p. 16-17) ao considerar que "só é possível ensinar aquilo que se sabe" destaca a importância de "oportunizar aos professores a compreensão de como podem lidar com as características pessoais no processo de 
aprender, demonstrando a possibilidade de mudanças na capacidade de sua organização cognitiva na reconstrução do conhecimento".

No processo de desenvolver-se profissionalmente, os professores tomam inúmeras decisões (conscientes ou não) sobre o que aprender, como fazê-lo, o que alterar em sua prática (ou não), o que alterar e/ou ampliar em seus saberes (ou não), etc. Nesse processo, dois elementos se destacam: a prática como fonte de indagações e inquietação, a partir da qual inicia-se o processo de reflexão; e o conhecimento de si. A prática, por um lado, é o elemento centro do desenvolvimento profissional, uma vez que torná-la mais significativa e eficiente para todos os envolvidos é o principal objetivo do desenvolvimento profissional. [...] Por outro lado, o conhecimento de si - de seus próprios saberes, limitações e potencial, das próprias metas e da prática - é um fator crucial no processo de desenvolver-se profissionalmente. É a partir desse conhecimento que o professor toma decisões e autorregula-se, acompanhando passo-a-passo o processo de aprender e mudar, reorientando-o sempre que necessário (FERREIRA, 2003, p. 45).

É principalmente na perspectiva deste conhecimento de si que foram conduzidas as escritas nas cadernetas de metacognição ao longo dos encontros na disciplina de Metodologia do Ensino de Matemática. Utilizamos pequenos cadernos distribuídos à turma para que diariamente escrevessem sobre seus aprendizados, concepções e percepções. A escrita dos cadernos funcionou como um diário, o qual possibilitou o acompanhamento de seus processos formativos ao longo da disciplina, sendo um material que ficou em posse das acadêmicas de modo que pudessem retomar suas leituras e revisitar emoções e aprendizados nele registrados.

Quando escrevemos, eternizamos o que foi narrado. A escrita atravessa o tempo, possibilitando que hoje possamos saber o que se escreveu há milhares de anos. Ela também atravessa o espaço, pois podemos enviar histórias para diversos lugares do mundo. A escrita, portanto, apresenta um caráter de permanência e amplitude que a fala não consegue atingir. O caráter de permanência atingido pelo registro das histórias contadas possibilita a reavaliação e a crítica de nossas atuações passadas, veiculando atitudes e emoções em relação a elas (ALBUQUERQUE, 2012, p. 42-43).

A condução dos escritos ocorreu, por vezes, inspirada em estudos que destacam reflexões acerca dos processos cognitivos vivenciados e tendo como desencadeadoras de tais escritas questões como: "O que aprendi? Como aprendi? O que não aprendi? " (DAMIANI; GIL; PROTÁSIO, 2003; RIBEIRO, 2003). E, por vezes, em virtude de sermos atravessados por aquilo que se mostrava no âmbito deste estudo, acabamos por conduzir uma sugestão de escrita que pudesse conta de instigá-las a escrever sobre memórias, concepções e percepções vinculadas à escola e à Matemática.

Escrita enquanto diálogo, principalmente consigo, pois quando construímos a escrita ela está impregnada pelos questionamentos, pensamentos e curiosidades de quem a escreve, ainda que tenha como destino o outro ela nos permite inicialmente refletir sobre saberes, sentimentos e vivências (FIORAVANTE, 2014, p. 27). 
A escrita de abertura das cadernetas, por exemplo, teve como orientação o resgate das memórias quanto à escola e às experiências com a Matemática vivenciadas anteriormente ao ingresso na graduação. Foram, deste modo, revisitadas emoções e lembranças que puderam ser ressignificadas ao longo da disciplina. Emergiram lembranças de professores que marcaram (positiva e negativamente) as trajetórias, concepções sobre como estudar Matemática (repetir até decorar), autoconceitos (sempre fui boa, nunca fui boa), crenças sobre uma Matemática atrelada à Báskara e decorar fórmulas e tabuada. O que se percebe nas escritas é que por vezes têm um envoltório de emoções que bloqueiam a percepção de nossas potencialidades quanto a determinados conteúdos. É nessa perspectiva que os afetos, memórias e concepções/crenças ganharam espaço em nossas cadernetas junto das clássicas questões (o que aprendi, como aprendi, o que não aprendi).

O autor tem na escrita a oportunidade de dialogar com ele mesmo, provocando seus pensamentos para procurar entender-se melhor. As experiências podem emergir no ato de escrever num exercício de revelarse para si e para interlocutores mesmo que virtuais. Neste processo, o escrevente busca a superação de problemas e por meio da interação com outros e consigo mesmo pode recordar e superar situações que antes não conseguiria (ALBUQUERQUE, 2012, p. 37).

As acadêmicas ao escreverem nas cadernetas foram levadas ao contato consigo mesmas, segundo Ferreira (2003, p. 75-76) "ao entrar em contato consigo mesma a pessoa reflete sobre os próprios saberes e práticas e toma decisões no sentido de continuar aprendendo e transformando seus saberes e suas práticas". Para a autora "realizar essas ações de modo intencional, agindo deliberadamente no sentido de se autorregular é ser apropriadamente metacognitivo" (FERREIRA, 2003, p. 76). Ramos et al. (2016, p. 48) reforça que ao escrever o professor em formação "permite-se questionar a respeito das suas capacidades, competências e ações, ao mesmo tempo em que toma consciência do que já sabe e o que ainda precisa saber. E, assim, assume compromissos e projeta seus ideais tanto profissionais quanto pessoais". Acreditando na potencialidade da escrita no que tange, principalmente, aos processos metacognitivos envolvidos na ação deste olhar para si é que foram conduzidas as escritas que no próximo tópico serão apresentadas com o resgate de algumas unidades de significado que permitem um panorama do que se mostrou neste processo de escrita realizado pelas acadêmicas que compuseram este estudo.

\section{Sobre as escritas - análise e emergências}

Por conduzirmos a pesquisa sob um viés fenomenológico, fomos levados a buscar uma metodologia de análise que permitisse a exploração dos dados de modo que se fizesse presente esta atitude fenomenológica diante da qual lidamos com uma pesquisa mais fluida e que se mostra conforme olhamos para os dados permeados por nossa indagação inicial ${ }^{6}$. Aproximamo-nos, assim, da Análise Textual Discursiva (ATD), com a finalidade de produzir novas compreensões sobre os fenômenos e discursos (MORAES; GALIAZZI, 2011).

\footnotetext{
${ }^{6}$ Como se mostram os afetos em relação à Matemática na escrita de acadêmicas de um curso de Pedagogia de uma universidade pública do sul do Estado do Rio Grande Sul?
} 
A ATD se apresenta como um processo auto organizado e emergente no qual não são testadas hipóteses a fim de comprová-las, mas sim é realizada a busca da compreensão, reconstruindo conhecimentos existentes sobre os temas investigados. No caso de nosso estudo, lidamos com a reconstrução do dito nos escritos das acadêmicas no sentido de permitir-nos compreender como se mostram os afetos em relação à Matemática. Para realizar essas análises, seguimos uma sequência de três componentes: desconstrução dos textos do corpus, unitarização; estabelecimento de relações, categorização; captação do novo emergente, comunicação das compreensões atingidas.

Optamos por trabalhar com categorias emergentes, de modo que não dispúnhamos de classificações elaboradas a priori. Para proceder com a unitarização, inicialmente realizamos a delimitação do corpus, momento no qual fizemos a escolha de selecionar as escritas do primeiro e do último dia, de modo a contarmos com um total de 42 textos referentes às produções escritas das 21 acadêmicas que compareceram em ambos os encontros e concederam autorização para que pudéssemos utilizar seus materiais no estudo.

As unidades de significado foram sendo identificadas e codificadas de modo a permitir situá-las facilmente nos textos originais, de forma que a eles pudéssemos retornar sempre que necessário. Optamos por elaborá-las com a sigla do nome das acadêmicas responsáveis pela autoria dos textos, pois ainda que não quiséssemos utilizar diretamente seus nomes, mantivemos de algum modo a identidade. O código 1NS2, por exemplo, corresponderia à segunda unidade (1NS2) extraída da escrita do primeiro dia (1NS2), da acadêmica Nome Sobrenome (1Nㄴ). Os textos analisados geraram um total de 106 unidades, as quais foram aproximadas de acordo com seus conteúdos, de modo a permitir a elaboração de categorias.

A análise acaba por ocorrer de maneira cíclica, pois são feitas inúmeras releituras dos escritos, até chegarmos às unidades de significado, as quais, mesmo depois de elaboradas, acabam sofrendo alterações conforme o fenômeno vai sendo compreendido. A unitarização leva à emergência de categorias, ou subcategorias, que podem levar a categorias mais amplas que permitam elucidar mais sobre o fenômeno: no caso, os afetos em relação à Matemática. Conforme as categorias emergem, as unidades também adquirem novos sentidos e acabam por dizer mais do fenômeno que se mostra, assim, a cada releitura podem ser apreendidas compreensões que permitam chegar à elaboração do metatexto, no qual os novos 'insights' sobre o tema estudado podem ser revelados.

As categorias que se mostraram através da reorganização das unidades de significado foram: percepção e metodologias; utilização e finalidades; cognição e saberes; emoção e sentimentos. Apresentaremos, nas linhas que seguem, a caracterização das quatro categorias e por fim um resgate quanto a aspectos metacognitivos que puderam ser percebidos nas escritas.

Ao debruçar o olhar sobre os dados da pesquisa a metacognição se mostrou significante corroborando a validade da metodologia de escrita das cadernetas utilizada.

A primeira categoria a qual nos aproximamos remete às percepções acerca da Matemática e às metodologias de ensino utilizadas. Dentre tais percepções está a famosa associação da Matemática a um bicho de sete cabeças, o que na escrita das acadêmicas mostra-se como um constructo com base na forma como foram ensinadas e não como uma concepção definitiva do que seja a Matemática. Associada às metodologias de trabalho, fica evidente a presença da memorização, sendo esta posta como um fator 
bastante negativo vinculado à Matemática, pois ao decorar sem compreender, havia uma mecanização no sentido de meramente serem feitas repetições sem o entendimento do conteúdo. A presença de tais aspectos em relação à Matemática emerge de unidades como: "A tabuada tem que saber de cor e salteado é o que dizia meu pai. Assim, decorei, sei toda a tabuada, uso a calculadora quando estou com pressa, caso contrário, não" [1SI5]". "Quanto à minha experiência com a matemática, posso dizer que foi complicada no fundamental, pois os professores exigiam memorização de tabuada e memorização de fórmulas e tal e isto, era maçante e por isto não gostava" [1FB1]. As memórias expressas nas escritas das cadernetas reforçam o que afirma Cunha (1991) quanto à representatividade que os professores do passado têm ao deixar marcas que muitas vezes podem, conforme apontam estudos, refletir no futuro comportamento docente destas acadêmicas. A pesquisadora destaca que tais relações precisam ser resgatadas, compreendidas e redimensionadas.

Ao pensarmos na segunda categoria - conhecimento matemático e os questionamentos acerca da utilização e finalidade - podemos tomar duas perspectivas que se apresentam ao trabalharmos com a Matemática: quando mecanicamente se busca o resultado correto, ou recorrentemente somos questionados, enquanto professores, sobre a utilidade daquilo que estamos ensinando (LORENZATO, 2006; MACHADO, 2012). Ao analisarmos as escritas temos a questão da utilização no sentido da aplicabilidade prática do conteúdo e finalidades no âmbito do que buscavam ao estudar e tentar aprender Matemática. Dentre as unidades representativas desta categoria temos:

1JB2 - Ao falar de matemática, me lembro da fórmula de Báskara, acho que pelo fato de tantas vezes ter repetido a fórmula para memoriza-la. Até hoje não sei por que aprendi aquilo, pois não uso p/nada. (hahaha) Espero que ao chegar no caminho de professora, quando chegar lá, eu consiga mostrar aos meus alunos os significados e a importância de estarem ali estudando, e que eles gostem dos conteúdos, e não façam só por fazer.

1MP4 - Quando chegou as fórmulas de báscara então aí complicou tudo, mas ainda bem que decorei as fórmulas e consegui passar de ano porque eu não via nenhuma utilidade de aprender aquilo tudo parecia não ter relação nenhuma com a vida real, pois se eu perguntasse quase sempre riam de mim porque eles, mesmo não entendendo, fingiam que entendiam.

Toledo e Toledo (2009) destacam como sendo uma pergunta comum entre os estudantes o: 'Para que eu preciso aprender isso? '. Os pesquisadores afirmam que "embora um dos objetivos explícitos do ensino da matemática seja preparar o estudante para lidar com atividades práticas que envolvam aspectos quantitativos da realidade, isso acaba não ocorrendo" (TOLEDO; TOLEDO, 2009, p. 7). O fato de ser apresentada para os estudantes uma Matemática que não remete a práticas com vínculo com a realidade é exatamente 0 que se mostra nas unidades acima. Nos trechos destacados vê-se o caráter metacognitivo das estudantes ao buscarem resgatar memórias de como ocorreram seus processos

\footnotetext{
${ }^{7}$ Apresentamos entre aspas e em itálico, juntamente do código utilizado em sua elaboração, as unidades de significado que julgamos pertinente resgatar nesta escrita.
} 
cognitivos em relação a um dos famosos conteúdos da Matemática, a fórmula de Báskara, porém este reafirma a memorização reforçando a desconexão com a realidade.

Ao tratarmos da terceira categoria elaborada temos a capacidade cognitiva e o domínio de conhecimentos matemáticos, que aqui são representados por aspectos tais como a superioridade intelectual muitas vezes atreladas à disciplina ou àqueles que a dominam. Como afirma 1JV5: "A imagem que tenho dos professores de matemática são gênios ou bruxos, pois esses causam medo e sabem o que mais ninguém consegue entender". Segundo Albarello (2014, p. 14) "parece ser senso comum que a Matemática é para indivíduos dotados de habilidades diferenciadas. E essa postura talvez venha de épocas em que essa área de conhecimento era privilégio de alguns". Somos então, levados a refletir sobre o autoconceito que vamos construindo acerca de nossas capacidades e como a questão da inteligência pode ser percebida no âmbito da Matemática (LOPES, 2011, 2012; SILVEIRA, 2011). Nota-se aqui, em termos de metacognição, um entrelaçamento às questões vinculadas ao autoconceito no sentido de perceberem-se, ou não, como dotadas de habilidades e capacidade para aprender e compreender a Matemática. A crença estabelecida de que a Matemática é para indivíduos com habilidades diferenciadas acaba por atuar no campo afetivo, no âmbito do autoconceito, e interferir no desempenho cognitivo, contudo a metacognição pode levar a repensar tais aspectos.

A quarta categoria refere-se mais diretamente às emoções e sentimentos nas relações com a Matemática. É nesta categoria que estão mais declaradamente expressas as questões vinculadas ao gostar, não gostar, medos e fobias que atravessam as memórias e relações com a disciplina. Aqui mostram representatividades unidades que expressam também esses afetos potencializados, a paixão pela disciplina como em 1TD1: "Sempre fui apaixonada pela matemática, resolvia cálculos e desafios com facilidade, conseguindo entender e pegar o gosto pelos números", ou pelo contrário, o ódio: "Partindo do princípio que eu odeio matemática desde os primórdios da minha escolarização, penso que a disciplina, que me assusta, pode, quem sabe, mudar a minha visão" [1JD1]. Contudo, nem sempre o ódio se mostrou em relação à disciplina, mas, por vezes, restringiu-se ao professor responsável por algum episódio ruim vivenciado na relação com a Matemática.

1SA2 - Na $7^{a}$ série, mesmo sabendo toda matéria, e resolvendo a maioria dos cálculos de cabeça, e acertando quase que 100\%, acabei por repetir de ano, por causa da matemática, no entanto, isto nunca fez com que eu passasse a odiar matemática, no entanto a Shirlei, a tal professora de matemática, a esta sim, direcionei todo o ódio a ela.

Alguns associam os sentimentos, em relação à Matemática, aos professores que tiveram; enquanto outros, remetem-se diretamente ao entendimento da disciplina. Esta relação com o professor é enfatizada em 1AD1: "Em relação às lembranças da matemática, sempre disse que não gostava, até hoje na verdade penso que sei muito pouco, pois sempre relacionei a matéria ao professor. Se eu gostasse do professor, gostava de Matemática". E, salientando o vínculo com a disciplina em si, 2AD3 frisa que: "Geralmente gosta da Matemática quem a entende, por isso a importância do ensino ser realizado de forma que os alunos compreendam o real sentido de cada conteúdo". Podemos notar que tanto em um aspecto, quanto em outro, as relações acabam por ocorrer com determinados vínculos com o professor, seja pela figura que representa ou pelas metodologias que utilizam para mediar o trabalho com a Matemática. O recurso metacognitivo permite a tomada de consciência em relação a si (FERREIRA, 2003), o que envolve refletir e analisar possibilitando a 
consciência de seu próprio aprender (CARVALHO, 2007), podendo ajudar a identificar o que são problemas em relação ao aprender Matemática e suas habilidades ou impressões afetivas com professores, metodologias e circunstâncias.

Notamos que à Matemática entrelaçam-se as memórias, crenças, saberes, percepções em uma visão e compreensão que vai além da relação com a disciplina, mas inclui a percepção de si em meio a este contexto e aproximamo-nos da metacognição (FERREIRA, 2003; FLAVELL, 1979; JOU SPERB, 2006). Ao nos referirmos às percepções de si, destacamos a ideia do autoconceito (CARVALHO, 2009; GÓMEZ CHACÓN, 2003) que tais acadêmicas têm sobre suas capacidades e dificuldades diante da disciplina, o que fica expresso em:

1SI4 - Em relação as demais disciplinas, sempre fui boa aluna, meus pais não compreendiam o porquê de tamanha dificuldade. Dessa forma, introjetei que realmente a matemática eu só teria como meio de sobrevivência.

1AF1 - Bom, posso iniciar dizendo que... embora não seja muito boa com a matemática (atualmente) já me sai muito bem.

1TD1 - Sempre fui apaixonada pela matemática, resolvia cálculos e desafios com facilidade, conseguindo entender e pegar o gosto pelos números.

Tais escritas dizem tanto dos aspectos vinculados ao aprender, quanto das percepções sobre si e crenças introjetadas. Na perspectiva metacognitiva, buscando identificar marcas em relação à Matemática, acabaram sendo evidenciadas as visões que têm de si enquanto alunas, mensurando o ser boa, ou não, ponderando a facilidade e o se sair bem na disciplina. Ainda no rol de crenças, temos a já mencionada associação da Matemática a um bicho de sete cabeças e é exatamente no âmbito desta reflexão que apresentamos a unidade a seguir:

2MP1 - Depois deste ano percebi que a Matemática se transforma em um bicho de sete cabeças quando o professor cria esse bicho para os alunos, pois pelo que aprendi em todos os anos de minha vida é que a matemática era complicada cheia de regras, isso porque na verdade não apreendi da maneira correta, pois a matemática se resume a uma lógica simples que se você compreende a base e os conceitos você compreende o mais complexo grau que aparecer.

É possível perceber que a acadêmica, ao refletir sobre a forma como esse bicho de sete cabeças foi construído, acaba por questionar a forma como aprendeu/apreendeu a Matemática. Consegue perceber que migra da noção de uma Matemática complicada e cheia de regras para a percepção de uma Matemática que requer a compreensão de uma lógica simples, em que ao compreender a base e os conceitos é possível, para ela, compreender o que puder surgir. No processo de escrita a acadêmica provoca seus pensamentos ao buscar compreender-se melhor, podendo assim não só recordar situações, mas superá-las (ALBUQUERQUE, 2012).

Se para algumas estudantes há uma certa clareza nas percepções quanto ao aprender Matemática ao longo da vida, para outras a ausência de marcas negativas mostra-se como uma provável facilidade quanto ao que era ensinado. 1JB1 - "Lembro de alguns conteúdos a partir da $4^{a}$ série, e quanto à matemática, acredito que entendia o que era ensinado, por não lembrar de momentos de trauma ou algo parecido". Nota-se que não há um pensar sobre o 
processo. O contato com a Matemática possivelmente ocorreu de uma maneira natural o que é esboçado na crença de que se não recorda de momentos traumáticos é porque entendia o que era ensinado.

1PA1 - Seguindo no que compreende a matemática, não posso dizer que não gostava, pois acredito que tive mais momentos bons e quando digo bons, estou querendo dizer que as matérias eram compreendidas facilmente, do que momentos ruins.

1PA2 - Porém, acredito que escolhi uma graduação voltada para as humanas por achar que tinha mais facilidade em escrever textos do que fazer contas. Nessa perspectiva, olhando hoje, não sei se tenho tanta certeza disso. (kkkk)

A compreensão do que era ensinado emerge também na escrita acima, porém aqui aparece também a crença que a acadêmica tem sobre suas habilidades. Ao destacar que escolheu uma graduação voltada para as humanas, expressa a maior facilidade que tinha em escrever textos do que fazer contas, porém ao refletir sobre tal escolha e crença acaba por colocar em questionamento tal perspectiva.

Ao refletir sobre os processos de aprendizagens envoltos na sua trajetória com a Matemática, uma das acadêmicas recorda de sua dificuldade ao aprender frações. Ao buscar compreender tal dificuldade a acadêmica percebe que na realidade sua dificuldade não esteve atrelada ao conteúdo em si. 1AF3 - "Atualmente acredito muito no "poder" que um professor tem de fazer com que o aluno goste ou se saia bem nas aulas. Isto me faz refletir, quando "aprendi" frações, não gostava da professora e internalizei que não conseguiria aprender".

A escrita sobre as marcas deixadas na trajetória escolar de cada uma faz emergir situações e memórias que dialogam com o processo de construção do professor em formação. As marcas deixadas, as dificuldades vivenciadas, refletem em aspectos a serem pensados de modo que enquanto professoras proporcionem outras perspectivas a seus alunos.

1JR1 - Bom minha relação com a matemática era de amor, até ingressar na sexta série, quando a minha professora, Maria Vieira, tornou a minha vida um terror.

1JR2 - Voltei a gostar de matemática só no primeiro ano do ensino Médio, quando o professor, Odair, me conquistou ao explicar os conteúdos de maneira com que eu entendesse no primeiro instante.

1JR3 - Quando me tornar professora, pretendo ensinar aos meus alunos um tipo de matemática simples, usando de artifícios atrativos, usando a ludicidade a nosso favor.

2JR2 - O ano de 2016 serviu para mostrar que a matemática é sim uma matéria que abre a nossa mente e nos faz enxergar mais longe. Que não é o monstro que a minha infância e juventude desenhou para mim, que o que houve, na verdade, foram maus usos de ferramentas que pudessem tratar com competência e cuidado os números e códigos que decifram o mundo.

2JR1 - Pensar em Matemática como algo não promovedor, é justamente pensar na forma como eu aprendi matemática, ou seja, de forma 
autoritária, amedrontadora, sem dinamismo e o mais estarrecedor, sem aprender Matemática.

Percebemos que mesmo as escritas sendo realizadas em uma perspectiva de olhar para si, para suas memórias e percepções, a figura dos professores que tiveram marcou fortemente as relações das acadêmicas com a Matemática. Nas unidades de significado acima percebemos inclusive o resgate do nome destes que marcaram a trajetória na educação básica. É esta pregnância da imagem do professor que faz com que pensemos nos processos formativos destas pedagogas e na necessidade de realizar tais processos de escrita e reflexões sobre si. Ao resgatar as memórias e organizá-las em suas escritas retomam crenças e vivências que podem gradualmente ser ressignificadas.

\section{Considerações}

O momento formativo do tornar-se professor coloca em conflito uma dupla posição que é o estar na condição de estudante e constituir-se em professor, uma simetria invertida que se faz desde os primeiros passos no ambiente escolar. Professores irão trabalhar em condições muito similares (ou nem tanto) àquelas que vivenciaram enquanto estudantes e junto disso vem introjetados os afetos vivenciados nestes períodos. Retomemos as concepções em torno da metacognição e pensemos na resposta às questões: o que aprendi? como aprendi? o que não aprendi? Evidente que ao pensar em ensino e aprendizagem tais questionamentos e reflexões são deveras importante, mas se desconectarmos tais ações dos afetos que as envolvem poderemos não atingir o potencial que gostaríamos tanto do conhecimento em relação a determinado conteúdo quanto de nós mesmos.

Se a pessoa tem fobia da Matemática mesmo que seja capaz de realizar operações, fazer inferências lógicas provavelmente procurará manter distância desta disciplina o quanto for possível. É o caso, por exemplo, de optar por Pedagogia ou Magistério por não haver cálculos ou proporcionar fugir da Matemática, situação mencionada por algumas das acadêmicas que compuseram este estudo e relatada em estudos como os de Thomaz (1996) e Carvalho (2009). Porém, as escritas analisadas permitiram perceber que ao narrarem/escreverem suas histórias (ALBUQUERQUE, 2012; FERREIRA, 2003; FIORAVANTE, 2014) emergiram situações nas quais as relações com a Matemática puderam ser ressignificadas no sentido de perceberem que por vezes os sentimentos estavam mais arraigados às pessoas que fizeram parte da trajetória de estudos do que com a disciplina em foco ou até mesmo com o autoconceito que tinham de si em relação às capacidades e dificuldades.

Quando nas cadernetas foram solicitadas a escrever o que aprendi, como aprendi e o que não aprendi na realidade já estávamos supondo que haveria um processo metacognitivo (LEITE; DARSIE, 2011) em ação já que a pessoa teria a percepção de tais fatos. Em nosso estudo percebemos que por vezes estão atrelados a esses aspectos outros que em geral não refletimos e muito menos escrevemos sobre. Afetos e memórias tanto servem como propulsores quanto em muitas situações como barreiras que nos impedem de acessar determinados conhecimentos. E se a forma para lidarmos com nossas barreiras seja mapeá-las e conhece-las através da escrita e do resgate de nossas memórias, que possamos nos permitir mais vezes esses encontros. Encontros de nós mesmos em um 
processo de escrita e retomada do que está envolto no aprender a aprender, do conhecimento sobre o conhecimento. Como olhar para o outro enquanto professores se não olharmos para nós enquanto seres aprendentes e que também percorrem caminhos similares nas relações não só com a Matemática, mas com o ensinar/aprender?

As atividades metacognitivas, quando aplicadas na formação dos professores, podem induzir um crescimento na prática docente, uma vez que pode influenciar na futura ação pedagógica, transferindo os resultados de sua experiência para a sua prática. A finalidade maior é integrar à docência uma prática nova: praticar um ensino fundamentado na metacognição (CARVALHO, 2007, p. 78).

Pensar no ensino de Matemática é justamente pensar na disciplina que por muitos é vista como o bicho papão ou bicho de sete cabeças já mencionado anteriormente. Debruçar o olhar sobre a presença da Matemática na formação de pedagogas é justamente refletir sobre a formação daquelas profissionais que irão apresentar a Matemática formalmente às crianças. Como elaborar práticas de ensino e aprendizagem de Matemática que permitam ao aluno uma apropriação de tais conhecimentos de uma maneira dinâmica e autônoma se a própria professora não tiver vivenciado a oportunidade de pensar e refletir sobre seus encontros com a Matemática? O trabalho com a metacognição permite esse olhar para si, para as crenças, percepções e a dinâmica deste constante ir e vir em torno do se constituir professora que ensina(rá) Matemática para crianças.

\section{Referências}

ALBARELLO, Quielen R. S. Um olhar sobre a Matemática: fobia ou encantamento? Dissertação (Mestrado em Educação) - Universidade Regional Integrada do Alto Uruguai e das Missões, Frederico Westphalen, 2014.

ALBUQUERQUE, Fernanda Medeiros de. Histórias de sala de aula nas rodas de professores de química: potência para a formação acadêmico-profissional. 2012. 110f. tese (doutorado) Universidade Federal do Rio Grande - FURG, Programa de Pós-Graduação em Educação em Ciências: Química da Vida e Saúde, Rio Grande, 2012.

BICUDO, Maria Aparecida V. (Org.). Filosofia da educação matemática: fenomenologia, concepções, possibilidades didático-pedagógicas. São Paulo: Editora UNESP, 2010.

BICUDO, Maria Aparecida V. (Org.). Pesquisa qualitativa segundo a visão fenomenológica. São Paulo: Cortez, 2011.

BOGDAN, Robert C.; BIKLEN, Sari K. Investigação qualitativa em educação. Porto: Porto Editora, 1994.

BUSTINGORRY, Sonia O.; MORA, Sandra J. Metacognicion: un camino para aprender a aprender. Estudios Pedagógicos, v. 34, n. 1, p. 187-197, 2008.

CARVALHO, Dione L. Metodologia do Ensino de Matemática. São Paulo: Cortez, 2009.

CARVALHO, Fernanda Antoniolo Hammes de. Reaprender a aprender: a pesquisa como alternativa metacognitiva. 2007. 150f. Tese (Doutorado em Educação) - Faculdade de Educação, PUCRS, Porto Alegre, 2007. 
CUNHA, Maria Isabel da. A relação professor-aluno. In: VEIGA, IIma Passos Alencastro. (Org.). Repensando a didática. Campinas: Papirus, 1991. p. 145-158.

DAMIANI, Magda F.; GIL, Robledo L.; PROTÁSIO, Michelle R.. A metacognição como auxiliar no processo de formação de professoras: uma experiência pedagógica. UNIrevista (UNISINOS. Online), v. 1, 2006.

FELICETTI, Vera Lucia. Um estudo sobre o problema da MATOFOBIA como agente influenciador nos altos índices de reprovação na $1^{\text {a }}$ série do Ensino Médio. Dissertação (Mestrado em Educação em Ciências e Matemática) - Pontifícia Universidade Católica do Rio Grande do Sul, Porto Alegre, 2007.

FERREIRA, Ana Cristina. Metacognição e desenvolvimento profissional de professores de Matemática: uma experiência de trabalho colaborativo. 2003. 390f. Tese (Doutorado em Educação) - Faculdade de Educação, Universidade Estadual de Campinas, SP, 2003.

FIORAVANTE, Ana Paula G. Escrita reflexiva na formação inicial de professores: vivências no Curso de Pedagogia da FURG. 2014. 115f. Dissertação (Mestrado em Educação) - Programa de Pós-graduação em Educação, Universidade Federal do Rio Grande - FURG, Rio Grande, 2014.

FLAVELL, John H. Metacognition and Cognitive Monitoring: a new área of cognitivedevelopmental inquiry. American Psychologist, v. 34, n. 10, october 1979.

GÓMEZ CHACÓN, Inés María. Matemática Emocional: os afetos na aprendizagem matemática. Tradução de Daisy Vaz de Moraes. Porto Alegre: Artmed, 2003.

JOU, Graciela I. I. de; SPERB, Tania Mara. A metacognição como estratégia reguladora da aprendizagem. Psicologia Reflexão e Crítica, v. 19, n. 2, p. 177-185, 2006.

KLÜBER, Tiago Emanuel; BURAK, Dionísio. A fenomenologia e suas contribuições para a Educação Matemática. Práxis Educativa, v. 3, n.1, 2008.

LEITE, Eliana A. P.; DARSIE, Marta Maria P. Implicações da metacognição no processo de aprendizagem da Matemática. Revista Eletrônica de Educação, São Carlos, SP: UFSCAR, v. 5, n. 2, p. 179-191, nov. 2011.

LOPES, J. P. Representação social da burrice em educação matemática: análise semióticopsicanalítica. In: SIMPÓSIO INTERNACIONAL DE PESQUISA EM EDUCAÇÃO MATEMÁTICA, 3, 2012, Fortaleza. Anais do... $3^{\circ}$ SIPEMAT, 2012.

LOPES, J. P. Representações sociais de professoras polivalentes sobre educação matemática. In: CONFERÊNCIA INTERAMERICANA DE EDUCAÇÃO MATEMÁTICA, 13, 2011, Recife. Anais da... XIII CIAEM, 2011.

LORENZATO, Sérgio. Para aprender matemática. Campinas: Autores Associados, 2006. (Coleção Formação de professores)

MACHADO, N. J. Matemática e educação: alegorias, tecnologias, jogo, poesia. 6. ed. São Paulo: Cortez, 2012. (Coleção questões da nossa época; v. 43)

MARTINS, Joel; BICUDO, Maria Aparecida V. Estudos sobre existencialismo, fenomenologia e educação. 2. ed. São Paulo: Centauro, 2006. 
MAXIMO, Marta; ABIB, Maria Lucia Vital dos Santos. Habilidades metacognitivas em atividades de resolução de problemas. In: CONGRESO INTERNACIONAL SOBRE INVESTIGACIÓN EN DIDÁCTICA DE LAS CIENCIAS, 9, 2013, Girona. Anais do... IX Congreso..., 2013, p. 2233-2237.

MORAES, R; GALIAZZI, M. C. Análise Textual Discursiva. Ijuí: Editora Unijuí, 2011.

PAPALEONTIOU-LOUCA, Eleonora. Metacognition and theory of mind. Newcastle, UK: Cabridge Scholars Pub., 2008.

PORTILHO, Evelise Maria L. A aprendizagem na universidade: os estilos de aprendizagem e a metacognição. In: ENCONTRO NACIONAL DE DIDÁTICA E PRÁTICA DE ENSINO, 12, 2004, Curitiba. Anais do... XII ENDIPE, 2004.

RAMOS, Tamires de Souza et al. Constructos em narrativas do ser e se fazer docente. Amazônia: Revista de Educação em Ciências e Matemáticas, v. 13, n. 25, p. 46-61, dez 2016.

REZENDE, Antônio M. Concepção fenomenológica de educação. São Paulo: Cortez; Autores Associados, 1990. (Coleção polêmicas do nosso tempo; v. 38)

RIBEIRO, Célia. Metacognição: um apoio ao processo de aprendizagem. Psicologia, Reflexão e Crítica, 2003, vol.16, n.1, pp.109-116.

ROMAINVILLE, M. Marc; NOËL, Bernadette; WOLFS, José-Luis. La métacognition: facetes et pertinence du concept em éducation. Revue Française de Pedagogia, v. 112, juillet-aoûtseptembre 1995, p.47-56.

SADOVSKY, Patrícia. O ensino de matemática hoje: enfoques, sentidos e desafios. Tradução de Antonio de Padua Danesi. 1. ed. São Paulo: Ática, 2010.

SECAFIM, Mariana F.; DARSIE, Marta Maria P. Estado da Arte de dissertações e teses sobre metacognição na Matemática no período de 1986 a 2016 no Brasil. In: SEMIEDU: Educação, diversidades culturais, sujeitos e saberes, 25, 2017, Cuiabá, MT. Anais do... $25^{\circ}$ SEMIEDU, 2017, p. 1-15.

SILVEIRA, M. R. A. A Dificuldade da Matemática no Dizer do Aluno: ressonâncias de sentido de um discurso. Educação e Realidade, v. 36, p. 45-63, 2011.

THOMAZ, Tereza Cristina F. Não Gostar de Matemática que fenômeno é este? Dissertação (Mestrado em Educação) - Pontifícia Universidade Católica do Rio Grande do Sul (PUCRS), Porto Alegre, 1996.

TOLEDO, M. B. A.; TOLEDO, M. A. Teoria e prática de Matemática: como dois e dois. São Paulo: FTD, 2009. 